\title{
Role of Proton-Coupled Electron Transfer in 0-0 Bond Activation
}

\author{
JOEL ROSENTHAL AND DANIEL G. NOCERA* \\ Department of Chemistry, 6-335, Massachusetts \\ Institute of Technology, 77 Massachusetts Avenue, \\ Cambridge, Massachusetts 02139-4307
}

Received March 14, 2007

\section{ABSTRACT}

The selective reduction of oxygen to water requires four electrons and four protons. The design of catalysts that promote oxygen reduction therefore requires the management of both electron and proton inventories. Pacman and Hangman porphyrins provide a cleft for oxygen binding, a redox shuttle for oxygen reduction, and functionality for tuning the acid-base properties of bound oxygen and its intermediates. With proper control of the proton-coupled electron transfer events, $\mathrm{O}-\mathrm{O}$ bond breaking of oxygen, and more generally oxygenated substrates, may be achieved with high efficiencies. The rule set developed for oxygen reduction may be applied to a variety of other small molecule activation reactions of consequence to energy conversion.

\section{Introduction}

The proton-coupled reduction of oxygen to water powers aerobic organisms. Oxygen reduction is coupled to intramembrane proton translocation, the free energy of which is used to drive the phosphorylation of ADP to generate ATP. ${ }^{1,2}$ Molecular oxygen is typically reduced along the two pathways shown in Scheme 1. Complete $\mathrm{O}_{2}$ reduction $\left(4 \mathrm{e}^{-}+4 \mathrm{H}^{+}\right.$, horizontal pathway) generates 2 equiv of water, whereas partial reduction $\left(2 \mathrm{e}^{-}+2 \mathrm{H}^{+}\right.$, diagonal pathway) yields $\mathrm{H}_{2} \mathrm{O}_{2}$. The $2 \mathrm{e}^{-} / 2 \mathrm{H}^{+}\left(E^{\circ}=-0.695\right.$ $\mathrm{V})$ and $4 \mathrm{e}^{-} / 4 \mathrm{H}^{+}\left(E^{\circ}=-1.229 \mathrm{~V}\right)$ reductions of $\mathrm{O}_{2}$ are both exergonic, but more than half a volt of energy is available from the latter reaction. ${ }^{3}$ It should therefore come as no surprise that the mammalian fuel cell, cytochrome $c$ oxidase $(\mathrm{CcO})$, evolved to drive complete $\mathrm{O}_{2}$ reduction selectively in order to maximize the energy available for ATP synthesis and to avoid the production of toxic reactive oxygen species such as peroxide and superoxide. ${ }^{4-6}$ For

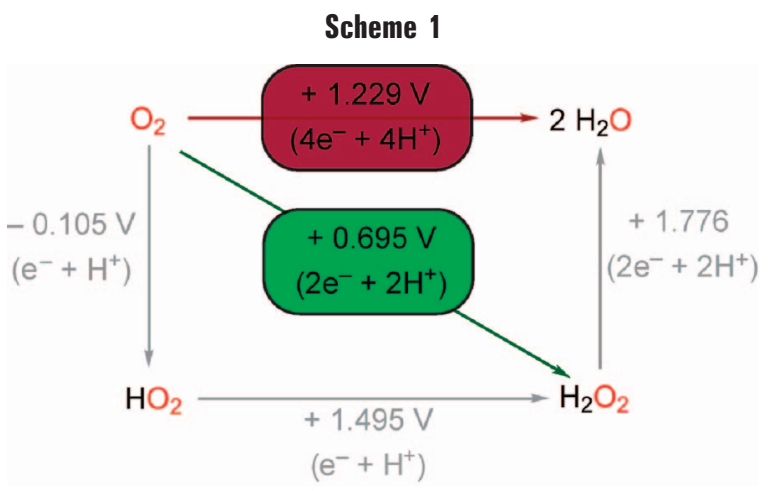

the same energetic reasons, maximum power generation from non-natural fuel cells relies on the incorporation of catalysts that perform the reduction of $\mathrm{O}_{2}$ completely and selectively and with no overpotential. ${ }^{7}$

Designers of synthetic $\mathrm{O}_{2}$ reduction catalysts have explored bimetallic cooperativity on the tenet that two metal centers working in concert might better promote chemical transformations along multielectron pathways by avoiding nonproductive and uncontrollable oneelectron/radical side reactions. Pioneering studies of Chang and Collman led to the development of the Pacman porphyrins, ${ }^{8,9}$ which are cofacial bisporphyrins anchored by a single rigid pillar. Such systems readily provide a faceto-face geometry with little lateral displacement between porphyrin subunits while allowing for the binding of oxygen within the Pacman "bite" of the cofacial cleft. Cofacial Pacman systems were confined to the two spacers, diporphyrin anthracene (DPA) and diporphyrin biphenylene (DPB), shown in Chart $1 .^{8}$ Cofacial DPA and DPB bisporphyrins containing either cobalt or iron are effective electrocatalysts for mediating the direct $4 \mathrm{e}^{-} / 4 \mathrm{H}^{+}$ reduction of oxygen in strongly acidic media..$^{8,10,11}$ The unique reactivity of the singly pillared DPA and DPB bisporphyrins as compared to that of doubly strapped bisporphyrin counterparts has been ascribed to their ability to maintain the face-to-face arrangement of porphyrin subunits while maintaining vertical flexibility via the Pacman effect. ${ }^{8}$ Nevertheless, the DPA and DPB systems of Chart 1 differ in vertical pocket size by only $\sim 1 \AA,{ }^{12}$ offering a limited range of conformational flexibility for examination of structure-reactivity relationships.

With an interest in examining the structural limits of vertical flexibility within the Pacman motif, we sought to develop methods for the facile assembly of new cofacial bisporphyrins that exhibit variable pocket sizes with minimal lateral displacements. To this end, the secondgeneration Pacman bisporphyrins based on the DPX (diporphyrin xanthene) and DPD (diporphyrin dibenzofuran) architectures shown in Chart 1 were targeted. The dialdehyde pillars needed for cofacial assembly are more easily obtained than for DPB and DPA, thereby streamlining the synthesis of the Pacman class of compounds. These second-generation cofacial bisporphyrins display an active multielectron catalysis that involves a proton-

\footnotetext{
*Corresponding author. E-mail: nocera@mit.edu.
} 


\section{Chart 1}

Original Pacman Assemblies
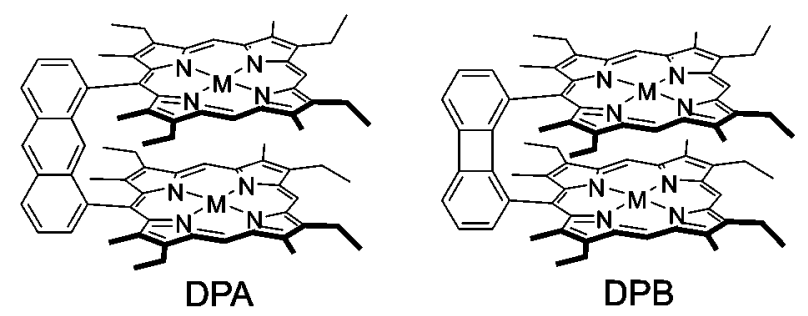

Second Generation Pacman Assemblies

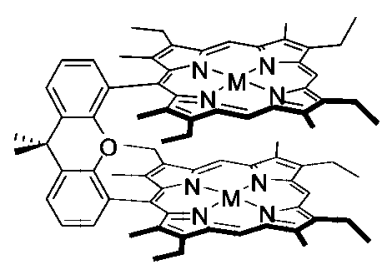

DPX

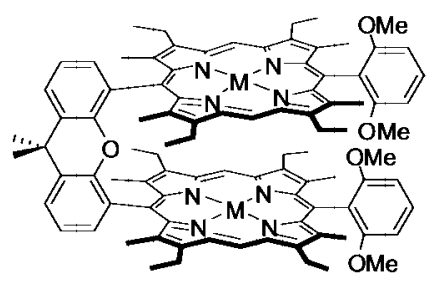

DPXM
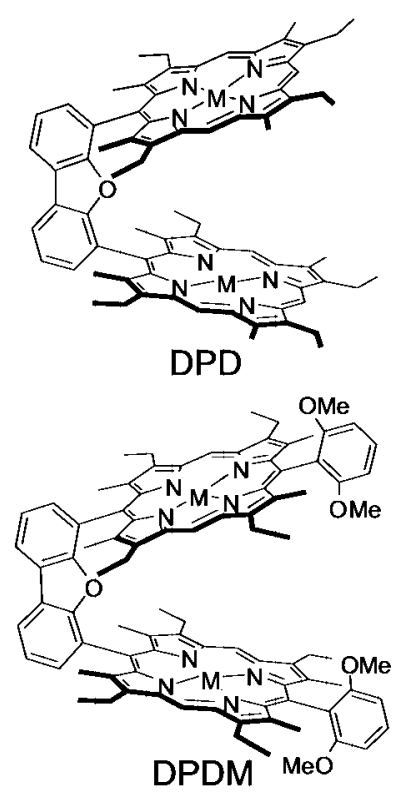

coupled electron transfer (PCET) reactivity. PCET reactivity can be further accentuated by removal of one porphyrin subunit from the DPX or DPD pillar and replacement by an acid-base functionality appropriately positioned over the remaining porphyrin platform. Much like the Pacman porphyrin constructs, these "Hangman" porphyrins exhibit an active multielectron activation chemistry driven by proton transfer. The PCET chemistry of these new Pacman and Hangman porphyrin constructs, especially as PCET pertains to oxygen activation, is the subject of this Account.

\section{Xanthene- and Dibenzofuran-Bridged Pacman Assemblies}

Installation of xanthene and dibenzofuran spacers into pillared cofacial bisporphyrin architectures was adapted from the resourceful use of these spacers by $\operatorname{Rebek}^{13}$ and $\mathrm{Cram}^{14}$ for supramolecular cleft design. The xanthenebridged cofacial bisporphyrin and the dibenzofuranbridged homologue are furnished from the three-branch approach of Figure $1,{ }^{15}$ which borrows from methods originally developed for the preparation of DPA and DPB Pacman derivatives. The first synthetic branch consists of the regioselective dilithiation of 9,9-dimethylxanthene or dibenzofuran in the presence of dry DMF followed by hydrolysis of the intermediate imidate salt. Both the xanthene and dibenzofuran dialdehyde bridges (salmon panel) are afforded in high yield via this facile one-pot reaction. The second branch of Figure 1 entails the synthesis of $\alpha$-free pyrrole ethyl ester (blue panel) via a five-step procedure using a Barton-Zard strategy, whereas the third branch delineates the preparation of the appropriate dipyrrylmethane dialdehyde (yellow panel) by a typical seven-step methodology. ${ }^{16}$ The Pacman is constructed by the convergent three-branch coupling of dicarboxaldehyde bridges with the appropriate $\alpha$-free pyrrole ethyl esters and dipyrrylmethane dialdehydes. The free-base cofacial bisporphyrins $\mathrm{H}_{4}(\mathrm{DPD})$ and $\mathrm{H}_{4}(\mathrm{DPX})$ are obtained in 15 and 16 steps, respectively, in an overall yield of $3 \%$. For comparison, the related DPA- and DPBbridged bisporphyrins $\mathrm{H}_{4}(\mathrm{DPA})$ and $\mathrm{H}_{4}(\mathrm{DPB})$ are synthesized in 20 and 23 steps, respectively. The economy of synthesis for the DPX and DPD Pacman porphyrins arises from the one-pot synthesis of the dialdehyde pillars (salmon panel), as compared to the DPA and DPB systems, which require five to eight synthetic steps to deliver the respective dialdehydes.

The span in the cleft size of the DPX and DPD Pacman architectures is in evidence from their molecular structures. $\mathrm{M}$ (II) ions reside in $\mathrm{N}_{\text {pyrrole }}$ squares, which are confined in a face-to-face arrangement by the xanthene and dibenzofuran bridges with little lateral displacement. Figure 2 summarizes the average dimensions of the molecular clefts that are conferred by the DPX and DPD bridges. ${ }^{17}$ The DPD spacer engenders clefts with dimensions of $\sim 7.5 \AA$, whereas the DPX gives a cleft dimension of $\sim 4 \AA .{ }^{18}$ We note, however, that the DPD framework itself is extremely flexible and is able to span large vertical dimension. The metal-metal distances of DPD can range from $3.504 \AA$ for $\mathrm{Fe}_{2} \mathrm{O}$ (DPD), which clamps its Pacman bite around a bridging oxo ligand, to $7.775 \AA$ for $\mathrm{Zn}_{2}$ (DPD) ${ }^{19}$ which allows the DPD platform to attain its natural splayed conformation. The spring action of the $\mathrm{Fe}_{2}$ (III,III) $\mu$-oxo Pacman clefts ${ }^{20,21}$ has been exploited for the selective photochemical oxidation of olefins ${ }^{22}$ and hydrocarbons. ${ }^{23}$ Pacman porphyrins bearing DPX and DPD pillars have electronic excited states ${ }^{24,25}$ from which a photochemistry may be derived. Ultrafast laser studies reveal that a mixed-valence $\mathrm{Fe}(\mathrm{II}) \mathrm{Fe}(\mathrm{IV})=\mathrm{O}$ intermediate is produced upon light excitation:

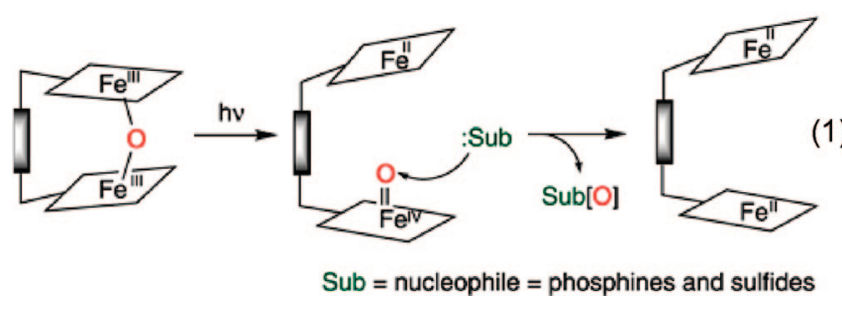

The intermediate may be trapped by substrate prior to reclamping. Transient absorption measurements show that the spring action of the bisporphyrin cleft is important in stereoelectronically controlling the side-on attack of the substrate on the photogenerated ferryl oxidant.

The pocket sizes of bisporphyrins may be further tuned by the selective introduction of sterically demanding aryl 
Branch 1: Bridge

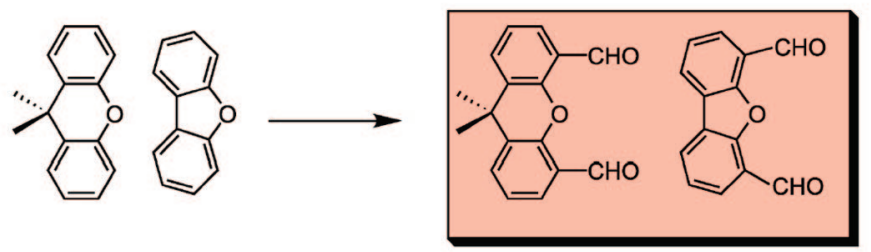

\section{Branch 2: Pyrrole}

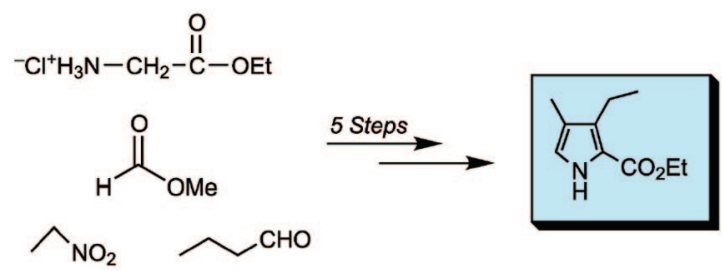

\section{Branch 3: Dipyrrylmethane}
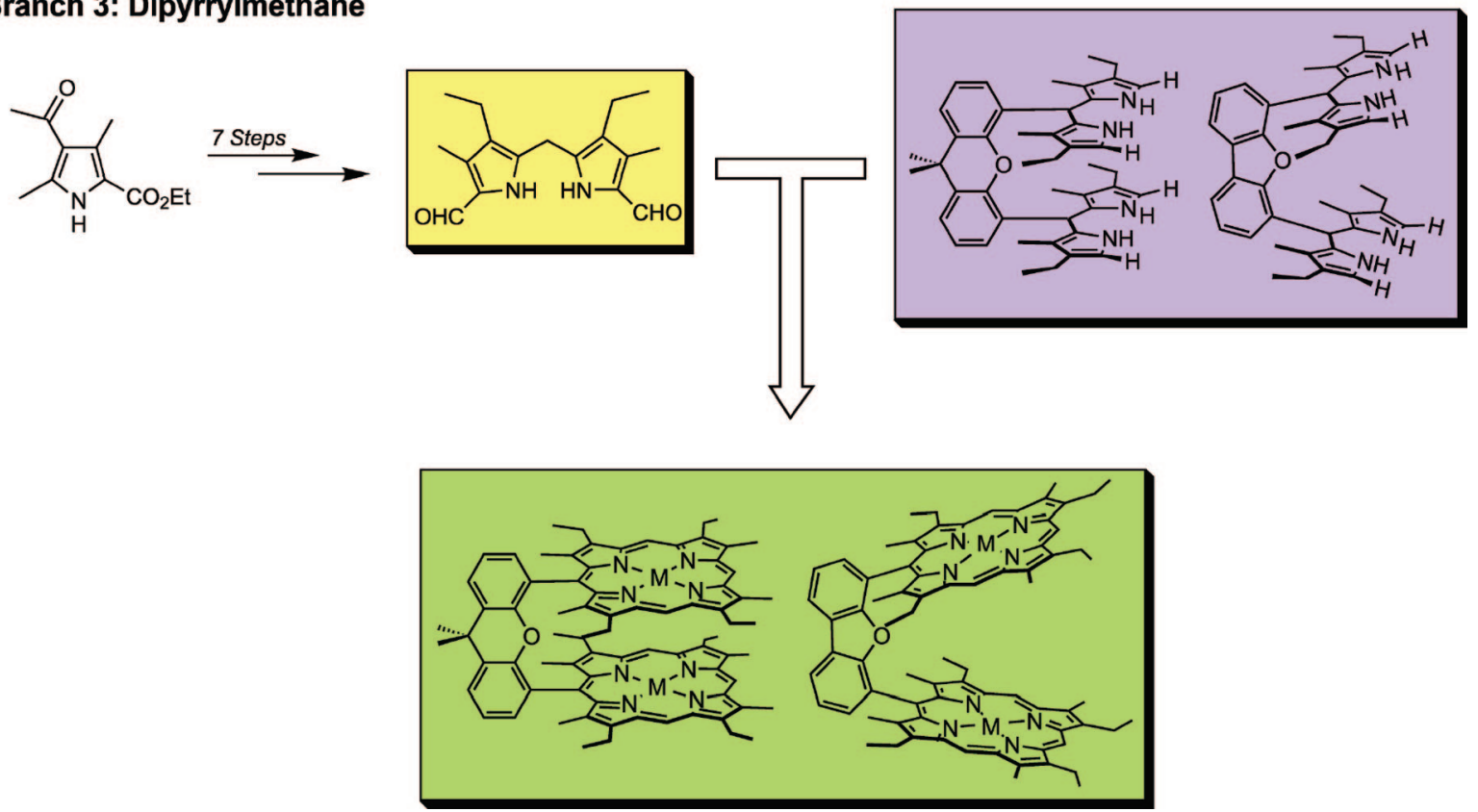

FIGURE 1. Flow diagram detailing the three-branch convergent methodology for the synthesis of cofacial Pacman bisporphyrin architectures.
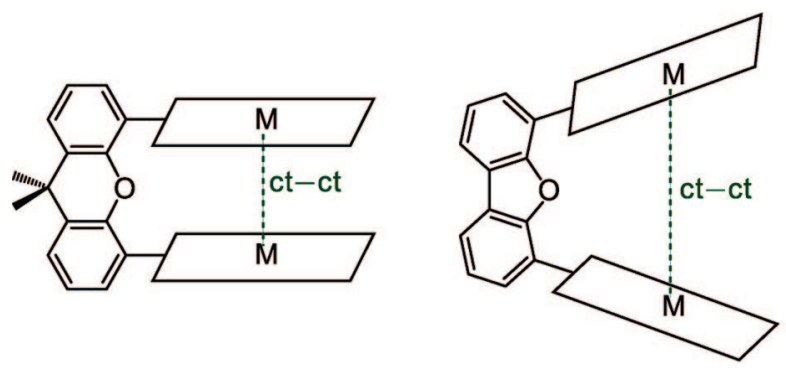

\begin{tabular}{lcc} 
& \multicolumn{2}{c}{$d_{\mathrm{ct}-\mathrm{ct}}(\AA)$} \\
\cline { 2 - 3 } $\mathrm{M}$ & $\mathrm{DPX}$ & $\mathrm{DPD}$ \\
\hline $\mathrm{H}_{2}$ & 4.002 & 8.220 \\
$\mathrm{Zn}$ & 3.863 & 7.587 \\
$\mathrm{Pd}$ & 4.001 & 6.781 \\
$\mathrm{Cu}$ & 4.698 & $\mathrm{NA}$ \\
$\mathrm{Ni}$ & 3.978 & $\mathrm{NA}$ \\
\hline Avg & 4.108 & 7.529
\end{tabular}

FIGURE 2. Schematic representation of the crystallographic metrics obtained for several DPX and DPD Pacman derivatives. The value $d_{\text {ct-ct }}$ corresponds to the intermetallic distance for the Pacman complexes.

groups trans to the rigid xanthene or dibenzofuran bridge. Aryl-substituted dipyrrylmethane dialdehydes are conveniently supplied via a three-step procedure from a pyrrole and an aldehyde. ${ }^{26}$ The convergent three-branch approach shown in Figure 1 permits bulky groups such as methoxyaryls to be installed in the meso position, opposite the bridge [diporphyrin xanthene methoxyaryl (DPXM) and diporphyrin dibenzofuran methoxyaryl (DPDM)]. ${ }^{27}$ By employing appropriate substituents along the periphery of the macrocyclic superstructure, we are able to tune the pocket sizes of the Pacman motif over a series of metalmetal distances ranging from 4.0 to $>8.0 \AA .{ }^{17}$ 


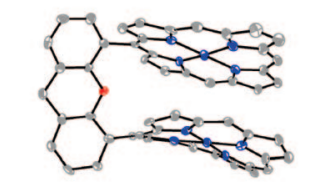

$\mathrm{Co}_{2}(\mathrm{DPX})(\mathrm{M}-\mathrm{M}=4.53 \AA)$

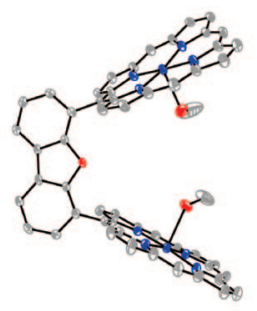

$\mathrm{Co}_{2}(\mathrm{DPD})(\mathrm{M}-\mathrm{M}=8.62 \AA)$

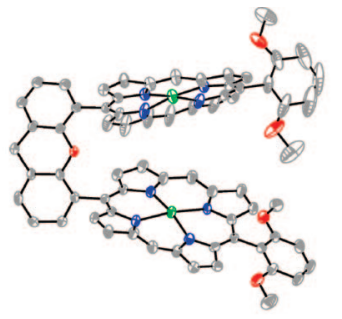

$\mathrm{Co}_{2}$ (DPXM) (M-M = 5.91 $\AA$ )

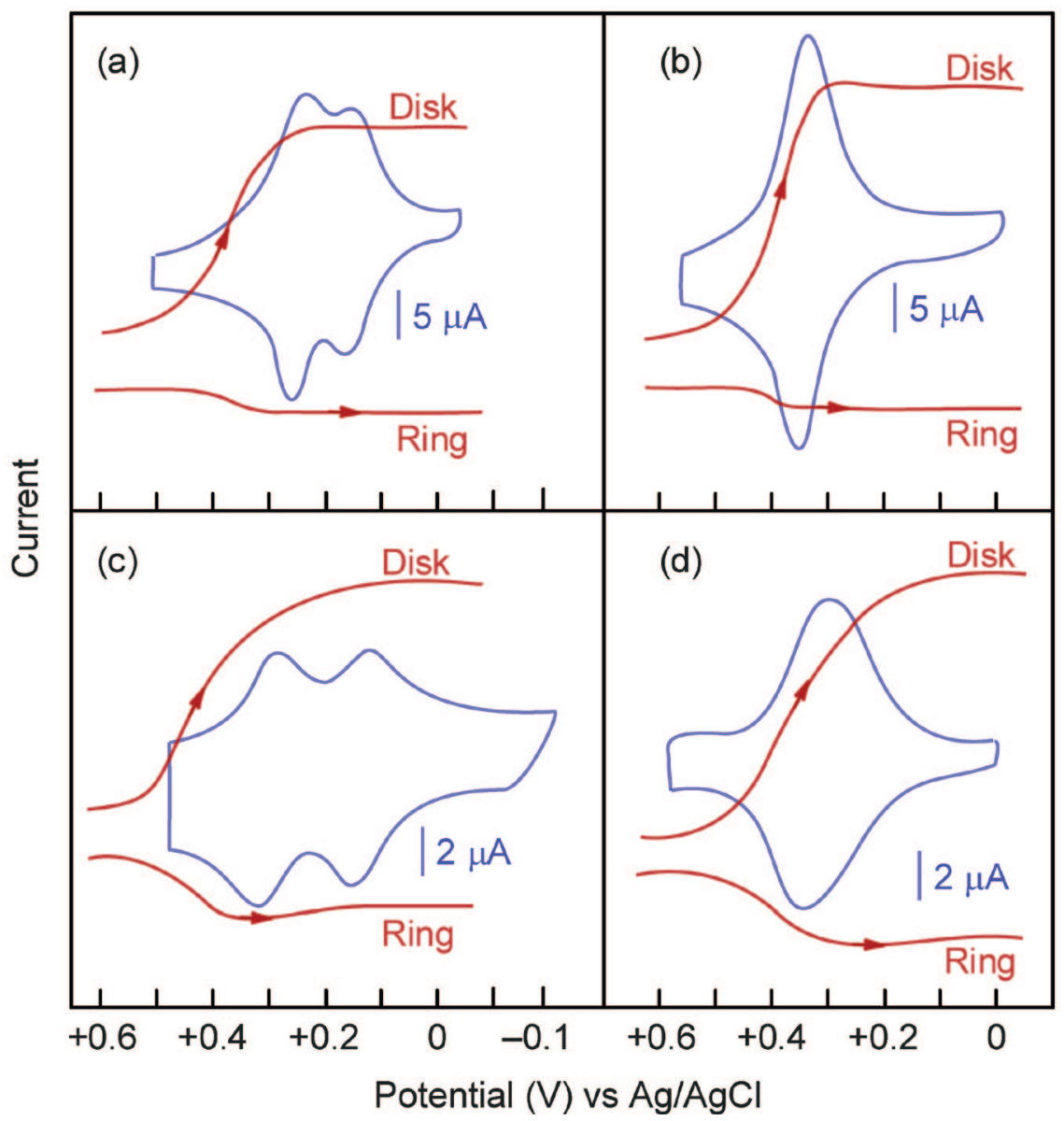

FIGURE 3. Thermal ellipsoid plots (top) for $\mathrm{Co}_{2}(\mathrm{II}, \mathrm{II})$ Pacman porphyrins that function as $\mathrm{O}_{2}$ reduction catalysts and overlay of cyclic voltammetric responses (blue) and rotating Pt ring-disk voltammograms (crimson) (bottom) for reduction of $\mathrm{O}_{2}$ at pyrolytic graphite disks coated with (a) $\mathrm{Co}_{2}(\mathrm{DPX})$, (b) $\mathrm{Co}_{2}(\mathrm{DPD})$, (c) $\mathrm{Co}_{2}(\mathrm{DPXM})$, or (d) $\mathrm{Co}_{2}(\mathrm{DPDM})$. The amount of $\mathrm{H}_{2} \mathrm{O}_{2}$ product produced from $\mathrm{O}_{2}$ reduction can be calculated from the ratio of the ring current, due to $\mathrm{H}_{2} \mathrm{O}_{2}$, with respect to the total reduction current at the catalyst-coated graphite disk.

\section{Oxygen Reduction by Cobalt Pacman Complexes}

Dicobalt(II) cofacial bisporphyrins are prominent among molecular catalysts for mediating the selective $4 \mathrm{e}^{-} / 4 \mathrm{H}^{+}$ reduction of oxygen to water. As discussed by Taube, ${ }^{28}$ these systems attain their reactivity by fulfilling two general requirements. (i) They bypass one- and twoelectron redox transformations through bimetallic redox cooperativity, and (ii) they hinder the protonation and release of the two-electron peroxo-type intermediates. This reactivity model, however, does not rationalize all observations. Electron transfer of porphyrins at electrode surfaces is not necessarily rate-determining, and hence, a bimetallic cooperativity is not needed for some $\mathrm{O}_{2}$ reduction electrocatalysts. ${ }^{29}$ Additionally, enhanced reactivity of some porphyrin electrocatalysts is observed when the second coordination site is empty or replaced with an appropriate Lewis acidic metal ion. ${ }^{17,30-32}$ With the goal of augmenting our current understanding of $\mathrm{O}_{2}$ reduction, the electrocatalytic and homogeneous $\mathrm{O}_{2}$ reduction chemistries of the four second-generation Pacman complexes shown in Chart 1 for $\mathrm{M}=\mathrm{Co}$ (II) were examined.

Electrochemical Reduction. The redox properties of the $\mathrm{Co}_{2}$ (II,II) Pacman porphyrins of Chart 1 have been examined using a thin-layer cyclic voltammetric technique. A single, reversible oxidative wave at $+0.33 \mathrm{~V}$ (vs $\mathrm{Ag} / \mathrm{AgCl}$ ) is observed for $\mathrm{Co}_{2}(\mathrm{DPD})$ (Figure 3), consistent with two noninteracting metal centers resulting from the 
large vertical cleft dimension $(d=8.62 \AA)$. Conversely, the more compressed structure engendered by the xanthene spacer of $\mathrm{Co}_{2}(\mathrm{DPX})(d=4.53 \AA)$ results in mixed-valence behavior, as two reversible electrochemical oxidations are observed at +0.28 and $+0.17 \mathrm{~V}$ versus $\mathrm{Ag} / \mathrm{AgCl}$. The splitting of the oxidation processes arises from strong interactions between two proximate porphyrin $\pi$ systems. ${ }^{33}$ The redox properties of the parent DPX and DPD systems are not significantly perturbed by introduction of the sterically demanding methoxyaryl group trans to the spacer. The mixed-valence behavior of $\mathrm{Co}_{2}(\mathrm{DPX})$ is displayed by $\mathrm{Co}_{2}(\mathrm{DPXM})$ at comparable potentials $\left(E^{\circ}=\right.$ +0.14 and $+0.33 \mathrm{~V} \mathrm{vs} \mathrm{Ag/AgCl)} .{ }^{34}$ Moreover, cyclic voltammograms of $\mathrm{Co}_{2}(\mathrm{DPDM})$ in nitrobenzene (Figure 3 ) give a single, reversible two-electron oxidative wave at a potential identical to that of the splayed derivative $\mathrm{Co}_{2}{ }^{-}$ (DPD) $\left(E^{\circ}=+0.33 \mathrm{~V}\right.$ vs $\left.\mathrm{Ag} / \mathrm{AgCl}\right)$.

The selectivity for the direct $4 \mathrm{e}^{-} / 4 \mathrm{H}^{+}$versus $2 \mathrm{e}^{-} / 2 \mathrm{H}^{+}$ reduction of oxygen to water by the $\mathrm{Co}_{2}$ (II,II) suite of Pacman porphyrins was evaluated using rotating ring-disk electrochemistry (RRDE). Current-potential responses for catalytic oxygen reduction at a rotating graphite disk/ platinum ring electrode coated with each of the complexes of Chart 1 are summarized in Figure 3. Dicobalt(II) Pacman complexes of both DPX and DPD are selective catalysts for the direct reduction of $\mathrm{O}_{2}$ to $\mathrm{H}_{2} \mathrm{O}$ over $\mathrm{H}_{2} \mathrm{O}_{2}$ with $72 \%$ and $80 \%$ selectivities, respectively. ${ }^{33,34}$ This selectivity is markedly attenuated by the installation of a methoxyaryl group onto the Pacman motif. $\mathrm{Co}_{2}(\mathrm{DPXM})$ catalyzes the reduction of oxygen at a positive potential of $+0.24 \mathrm{~V}$ ( $\mathrm{vs} \mathrm{Ag} / \mathrm{AgCl})$; however, only $52 \%$ of the reaction proceeds along the $4 \mathrm{e}^{-} / 4 \mathrm{H}^{+}$pathway to produce water, while DPDM catalyzes oxygen reduction at a potential of $+0.25 \mathrm{~V}$ (vs Ag/AgCl) with $46 \%$ going directly to water. ${ }^{34}$

Chemical Reduction. Oxygen reduction catalysis may be independently examined by chemical means using ferrocene as the chemical reductant and proton sources of varying acidities. ${ }^{35}$ Such homogeneous $\mathrm{O}_{2}$ reduction experiments are powerful because they allow conversions to be investigated stoichiometrically as well as catalytically.

$\mathrm{O}_{2}$ reduction is monitored by following the conversion of ferrocene to ferrocenium via the two-electron (path A) and four-electron (path B) pathways shown in Figure 4. The number of electron equivalents that are consumed in this reaction can be easily assessed by monitoring the rise in ferrocenium absorbance. For the complete fourelectron reduction of $\mathrm{O}_{2}$ to water, the concentration of ferrocenium at the end of the reaction is equal to 4 times the initial concentration of $\mathrm{O}_{2}$ in solution. Conversely, for the 2 equiv reduction of $\mathrm{O}_{2}$ to $\mathrm{H}_{2} \mathrm{O}_{2}$, the concentration of ferrocenium at the end of the reaction is only 2 times the initial concentration of $\mathrm{O}_{2}$ in solution. Catalytic systems that produce intermediate amounts of both $\mathrm{H}_{2} \mathrm{O}_{2}$ and $\mathrm{H}_{2} \mathrm{O}$ will form ferrocenium at concentrations between the these two extremes. In this manner, the efficacy of $\mathrm{O}_{2}$ reduction by the various catalysts of Chart 1 may be ascertained.

Figure 4 shows the time courses for ferrocenium production for each of the catalysts in air-saturated benzonitrile solutions of ferrocene $(0.1 \mathrm{M})$ and $\mathrm{HClO}_{4}(0.02$
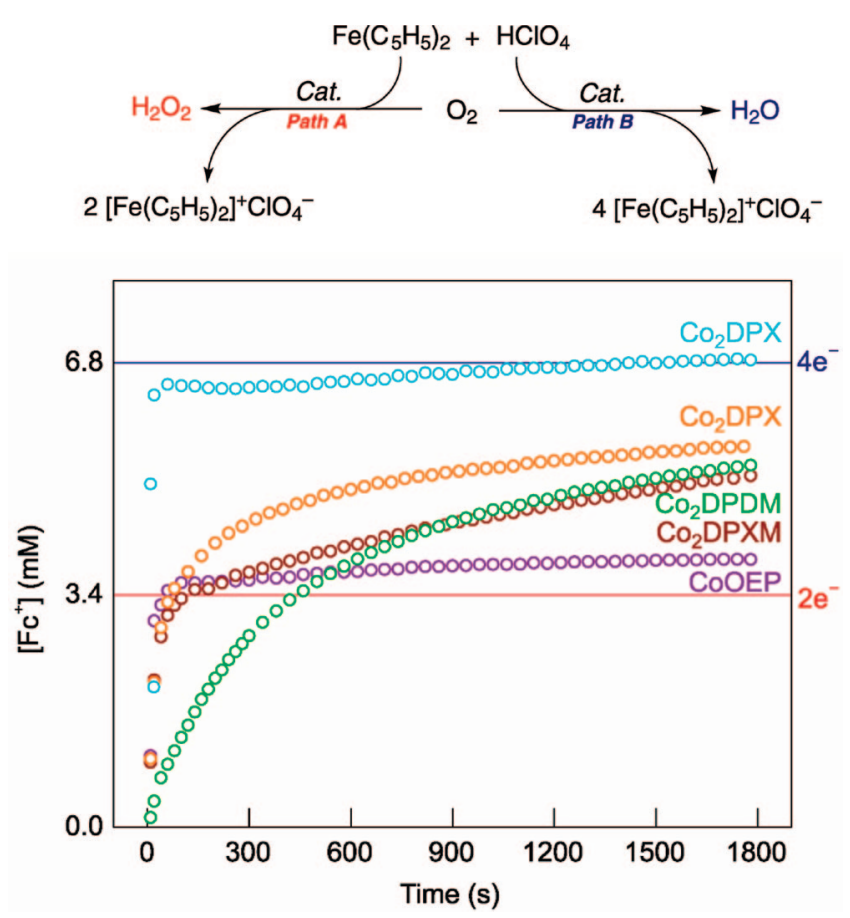

FIGURE 4. Reduction of $\mathrm{O}_{2}$ by ferrocene and perchloric acid under homogeneous conditions using the Pacman systems of Chart 1. Spectroscopic monitoring of the increase in ferrocenium concentration allows for the selectivity of each catalyst's performance along both $4 \mathrm{e}^{-} / 4 \mathrm{H}^{+}$and $2 \mathrm{e}^{-} / 2 \mathrm{H}^{+}$reduction pathways.

M). Given that the concentration of $\mathrm{O}_{2}$ in air-saturated benzonitrile is measured to be $1.7 \times 10^{-3} \mathrm{M}^{-1}$, one would expect to observe the final concentration of ferrocenium to approach $4 \times\left(1.7 \times 10^{-3} \mathrm{M}^{-1}\right)$ or $6.8 \mathrm{mM}$ for a catalyst that is completely selective for the four-electron pathway (path B). Conversely, a system that is completely selective for the two-electron pathway that produces $\mathrm{H}_{2} \mathrm{O}_{2}$ would generate a final ferrocenium concentration of $2 \times(1.7 \times$ $10^{-3} \mathrm{M}^{-1}$ ) or $3.4 \mathrm{mM}$. The five traces approach varying asymptotic values, indicating differences in catalyst performance. All four $\mathrm{Co}_{2}$ (II,II) Pacman porphyrin catalysts that were studied display a greater selectivity for the reduction of oxygen to $\mathrm{H}_{2} \mathrm{O}$ as compared to the monomeric control catalyst, CoOEP. As for the electrocatalytic reduction of oxygen, the $\mathrm{Co}_{2}$ (II,II) DPX-spaced Pacman catalyst shows the highest selectivity for the reduction of $\mathrm{O}_{2}$ to $\mathrm{H}_{2} \mathrm{O}$. The presence of $\mathrm{H}_{2} \mathrm{O}_{2}$ was independently confirmed by a standard sodium iodide assay; ${ }^{36}$ we note that control experiments show that oxidation of ferrocene by $\mathrm{H}_{2} \mathrm{O}_{2}$ on the time scale of the experiment is slow. The amount of $\mathrm{H}_{2} \mathrm{O}_{2}$ measured was consistent with the conversion yields of the stoichiometric reaction. In the case of $\mathrm{Co}_{2}(\mathrm{DPX})$, reduction of $\mathrm{O}_{2}$ to water was complete and no $\mathrm{H}_{2} \mathrm{O}_{2}$ was therefore detected. As shown by the comparative bar graph in Figure 5, the results of the homogenous $\mathrm{O}_{2}$ reduction experiments are in agreement with those obtained via the electrocatalytic approach. Pacman systems $\mathrm{Co}_{2}(\mathrm{DPX})$ and $\mathrm{Co}_{2}(\mathrm{DPD})$ are far more selective for the $4 \mathrm{e}^{-} / 4 \mathrm{H}^{+}$pathway in generating water than the corresponding methoxyaryl-substituted homologues. Given that the structural flexibility and redox 


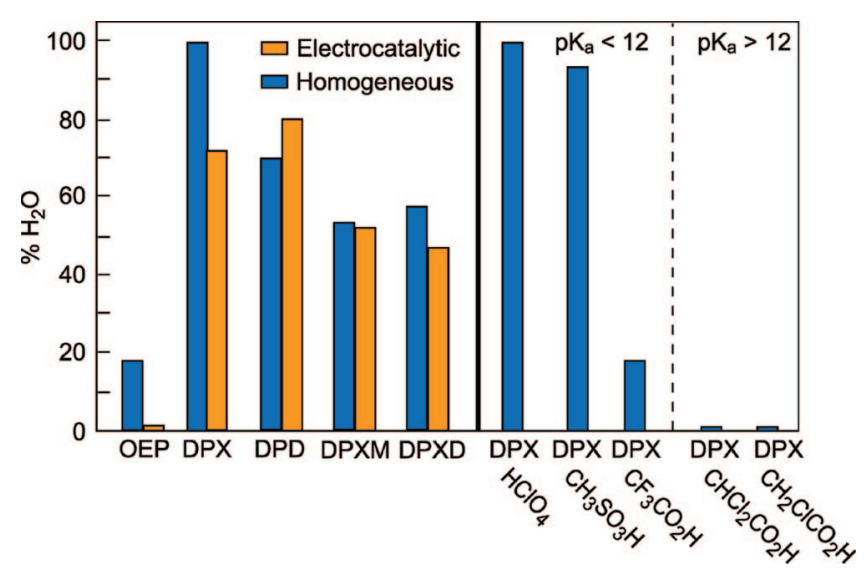

FIGURE 5. Efficiency of $\mathrm{H}_{2} \mathrm{O}$ production (left) from $\mathrm{O}_{2}$ by $\mathrm{Co}_{2}(\mathrm{II}, \mathrm{II})$ Pacman systems under homogeneous (Mets' blue) and electrocataIytic (Mets' orange) conditions. Effect of acid strength (right) on the course of $\mathrm{O}_{2}$ reduction by $\mathrm{Co}_{2}(\mathrm{DPX})$ as measured under homogeneous conditions. No reaction is observed when the acid $\mathrm{p} K_{\mathrm{a}}>12$.

behavior of the cofacial bisporphyrin systems are largely unperturbed by trans-aryl substitution, more subtle electronic and protonation factors were considered as causes for this change in catalytic selectivity.

\section{A PCET Mechanism for $\mathrm{O}_{2}$ Reduction by Pacman Constructs}

The disparate efficiencies for production of $\mathrm{H}_{2} \mathrm{O}$ from $\mathrm{O}_{2}$ between the $\mathrm{Co}_{2}$ (II,II) methoxyaryl-substituted Pacman architectures and the parent DPD and DPX complexes imply that the selective reduction of $\mathrm{O}_{2}$ to $\mathrm{H}_{2} \mathrm{O}$ as opposed to $\mathrm{H}_{2} \mathrm{O}_{2}$ steps beyond the idea of redox cooperativity between proximate metal centers. With the knowledge that $\mathrm{O}_{2}$ reduction requires both proton and electron equivalents, the role of proton delivery in determining $\mathrm{O}_{2}$ reduction pathways catalyzed by bimetallic systems was interrogated. ${ }^{34}$ DFT calculations show an inversion in the nature of the HOMOs for the $\mathrm{O}_{2}$ adducts of methoxyarylmodified and unmodified DPX and DPD Pacman porphyrins. Figure 6 shows the results for the oxygen adducts of the $\mathrm{Co}_{2}(\mathrm{II}, \mathrm{II}) \mathrm{DPX} / \mathrm{DPXM}$ congeners. The resting state for oxygen binding is the $\mathrm{Co}_{2}(\mathrm{II}, \mathrm{III})$ superoxo species; this is experimentally observed by EPR spectra, which show a symmetric 17-line spectrum for a symmetrically bound superoxide within the mixed-valence cleft of the Pacman porphyrin. ${ }^{33}$ For $\left[\mathrm{Co}_{2}(\mathrm{DPX})\left(\mathrm{O}_{2}\right)\right]^{+}$, the DPX superoxo species consists of localized molecular orbitals with significant $\pi^{*}(\mathrm{Co}-\mathrm{O})$ and $\pi^{*}(\mathrm{O}-\mathrm{O})$ character on the $\left[\mathrm{Co}_{2} \mathrm{O}_{2}\right]$ core. Conversely, the HOMO of the corresponding $\left[\mathrm{Co}_{2}-\right.$ (DPXM) $\left.\left(\mathrm{O}_{2}\right)\right]^{+}$intermediate is localized conversely on the porphyrin $\pi$ system with no electron density observed on the superoxo. Moreover, Mulliken population analysis reveals that the oxygen atoms of the superoxo within the DPX cleft are $\sim 20 \%$ more negatively charged than when in the DPXM cleft. Since protonation is expected to occur at the more basic site, the oxygens of the DPX molecule are predicted to be the target of protonation.
Taken together, these results have led to the mechanistic model shown in Figure 7. The cycle emphasizes the role of PCET activation for $\mathrm{O}-\mathrm{O}$ bond cleavage. Our results indicate that the basicity ( $\mathrm{p} K_{\mathrm{a}}$ of conjugate acid $\sim 12.5$ in $\mathrm{PhCN}$ ) of the superoxo complex is the key determinant of the selectivity for $\mathrm{O}_{2}$ reduction. Proton transfer to the $\left[\mathrm{Co}_{2} \mathrm{O}_{2}\right]^{+}$superoxo core of $\left[\mathrm{Co}_{2} \text { (bisporphyrin) }\left(\mathrm{O}_{2}\right)\right]^{+}$triggers a two-electron transfer, bypassing one-electron production of a $\left[\mathrm{Co}_{2}\right.$ (bisporphyrin) $\left.\left(\mathrm{O}_{2}\right)\right]$ peroxo-type intermediate. Protonation followed by a two-electron transfer provides the necessary equivalents to result in $\mathrm{O}-\mathrm{O}$ bond cleavage. The net result is a three-electron transfer process that leads to $\mathrm{O}-\mathrm{O}$ bond cleavage, producing an oxohydroxy species (outer cycle of Figure 7). Subsequent reduction by an additional electron produces the fully reduced water product. This model is supported by the $\mathrm{p} K_{\mathrm{a}}$ dependence of the $\mathrm{Co}_{2}(\mathrm{DPX})$ reduction chemistry as summarized in Figure 5. Oxygen reduction is observed when the reduction is performed with acids possessing $\mathrm{p} K_{\mathrm{a}}$ values of $<12$ in benzonitrile (e.g., $\mathrm{HClO}_{4}, \mathrm{CH}_{3} \mathrm{SO}_{3} \mathrm{H}$, or $\mathrm{CF}_{3} \mathrm{CO}_{2} \mathrm{H}$ ); selective reduction is not observed if $\mathrm{p} K_{\mathrm{a}}>$ 12 (e.g., $\mathrm{CHCl}_{2} \mathrm{CO}_{2} \mathrm{H}$ or $\mathrm{CH}_{2} \mathrm{ClCO}_{2} \mathrm{H}$ ).

The observations of the selective reduction of $\mathrm{O}_{2}$ to $\mathrm{H}_{2} \mathrm{O}$ by the Pacman porphyrins of Chart 1 concur with the chemistry of $\mathrm{CcO}$. Spectroscopic and kinetic studies of partially and fully reduced enzymes establish that the $\mathrm{O}-\mathrm{O}$ bond is broken upon the addition of three electrons and one proton to produce the oxo-hydroxy product. ${ }^{37,38} \mathrm{We}$ believe that superoxide of the cofacial porphyrins is susceptible to release. Hence, if the superoxo is not sufficiently basic, one-electron reduction of $\left[\mathrm{Co}_{2} \text { (bisporphyrin) }\left(\mathrm{O}_{2}\right)\right]^{+}$ensues in the absence of a proton and peroxide is produced (inner cycle of Figure 7). Protonation of the superoxo permits the system to bypass peroxo-type intermediates and in doing so drive the necessary three-electron equivalents that result in $\mathrm{O}-\mathrm{O}$ bond cleavage.

The overall mechanism in Figure 7 is satisfying on several counts. First, as mentioned above, a proper stoichiometry of one proton and three electrons needed for $\mathrm{O}-\mathrm{O}$ bond cleavage is satisfied. Second, it clearly identifies the importance of the superoxo as the "resting state" for catalysis, a fact long known for the $\mathrm{O}_{2}$ reduction chemistry of Pacman porphyrins. ${ }^{39}$ Finally, the mechanistic cycle clarifies some perplexing observations that porphyrin templates bearing a distal metal-binding cap exhibit comparable selectivities for the four-proton, fourelectron pathway with or without a second redox-active metal ion bound in the distal cap. ${ }^{17,30,31}$ The mechanism shown in Figure 7 suggests that the second functional site, whether that be another porphyrin, a metal complex, or a metal-free coordination sphere, is to adjust the $\mathrm{p} K_{\mathrm{a}}$ of the protonated dioxygen adduct. Since a cooperative redox activity is not required from two cofacial porphyrins, the second site may be redox-inactive or completely absent. 

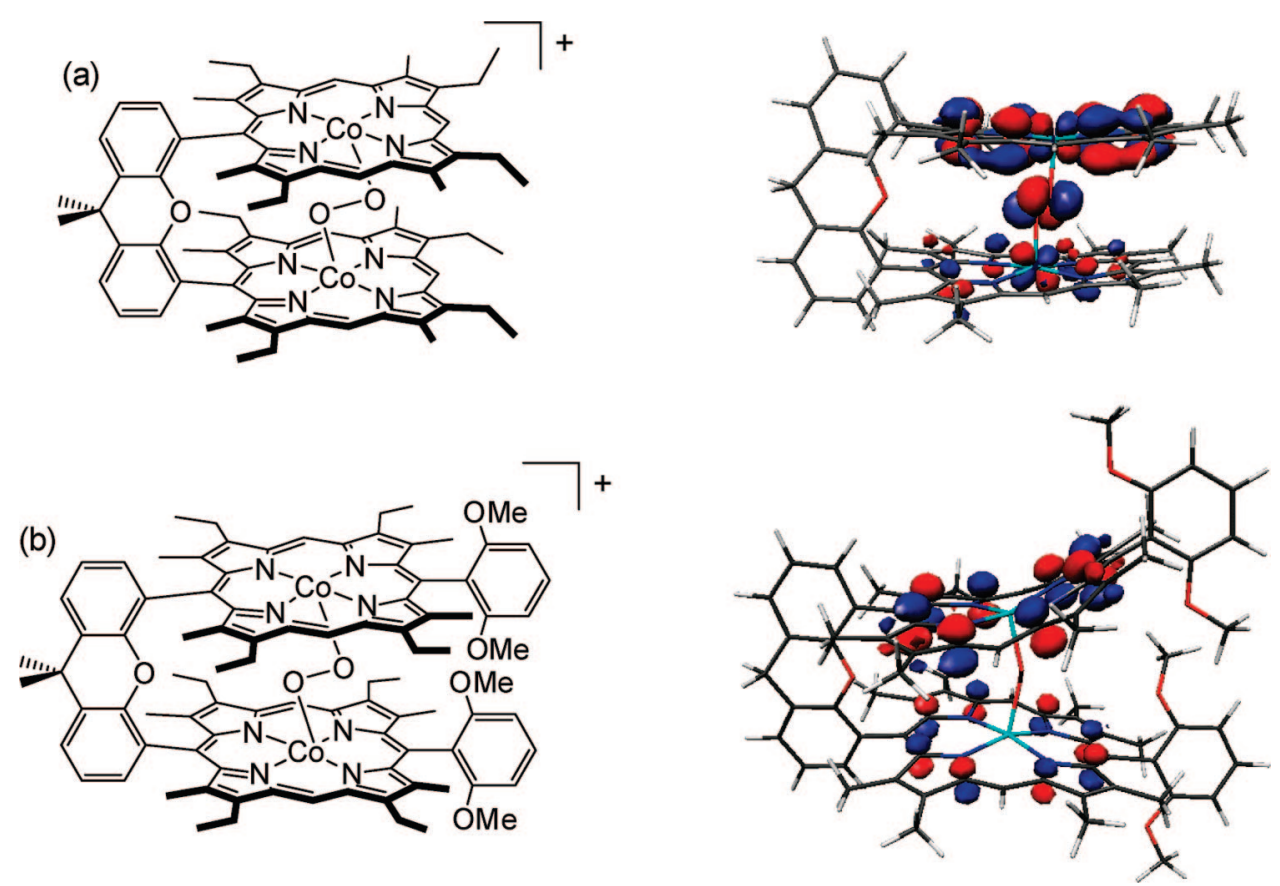

FIGURE 6. HOMO of the superoxide complexes of (a) $\left[\mathrm{Co}_{2}(\mathrm{DPX})\left(\mathrm{O}_{2}\right)\right]^{+}$and $(\mathrm{b})\left[\mathrm{Co}_{2}(\mathrm{DPXM})\left(\mathrm{O}_{2}\right)\right]^{+}$. $\mathrm{Co}_{2} \mathrm{DPX}$ has significant electron density at the bound oxygen and consequently is able to accept a proton to drive $0-0$ bond cleavage by PCET, and water is obtained. This is not the case for $\mathrm{Co}_{2} \mathrm{DPXM}$, which cannot be protonated, thus leading to peroxide as the oxygen reduction product.

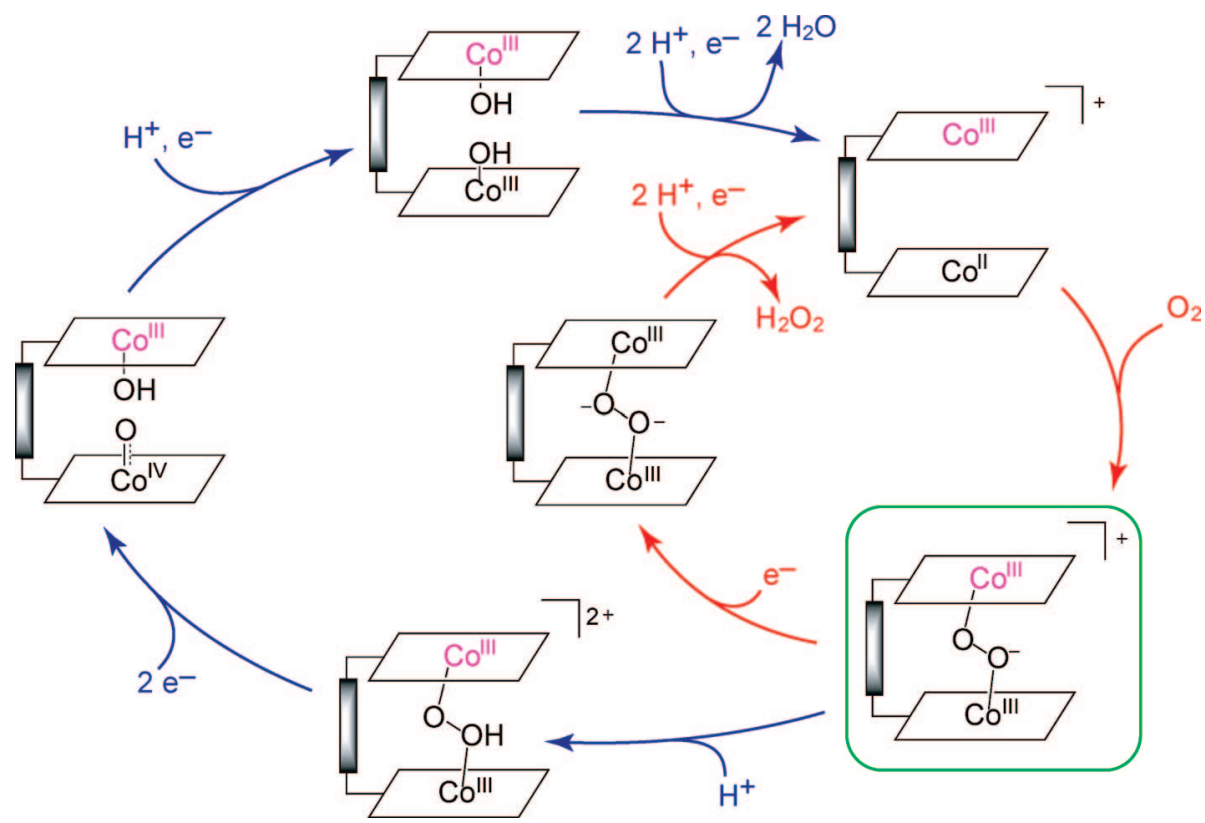

FIGURE 7. Cycle for $\mathrm{O}_{2}$ reduction by cofacial bisporphyrins. Protonation of the superoxo intermediate (highlighted with a box) is the key to efficient reduction of $\mathrm{O}_{2}$ to $\mathrm{H}_{2} \mathrm{O}$. The $\mathrm{p} K_{\mathrm{a}}$ value of the superoxide complex corresponds to the conjugate acid in benzonitrile. The top Co(III) ion (highlighted in violet) does not need to undergo a change in oxidation state to facilitate the $\mathrm{O}_{2}$ reduction chemistry.

\section{PCET 0-0 Bond Catalysis at Hangman Redox Platforms}

The Pacman porphyrins highlight the importance of properly controlling the proton inventory in achieving selective substrate activation, particularly for substrates involving $\mathrm{O}-\mathrm{O}$ bond activation. We sought to better control proton transfer at redox platforms, leading us to replace one porphyrin subunit of Pacman porphyrins with an acid-base group. This new active site, which we call a Hangman porphyrin, "hangs" an acid-base group above a $\mathrm{PFe}^{\mathrm{III}}(\mathrm{OH})$ ( $\mathrm{P}=$ porphyrin) redox platform via a xanthene or dibenzofuran spacer.

This new class of porphyrin compounds is obtained by the convergent approach shown in Figure 1, but with the xanthene aldehyde ester as the initial building block of the pillar. ${ }^{40}$ In this way, one appendage of the bridge is selectively protected. Treatment of this xanthene de- 


\section{Chart 2}

\section{Hangman Assemblies}
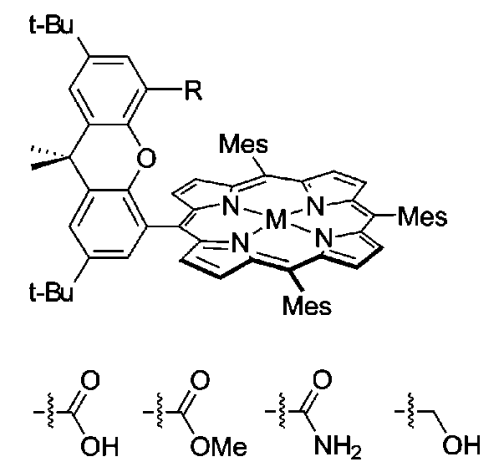

$\mathrm{R}=$

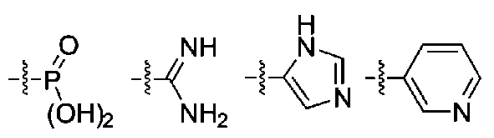

rivative with aryl aldehydes and pyrrole under standard Lindsey conditions affords a family of meso-substituted porphyrins bearing a singly functionalized xanthene spacer. Direct modification of the protected ester after macrocyclization proceeds smoothly to furnish the acid-base group. Alternatively, the ester can be converted directly or indirectly to a variety of other acid-base groups shown in Chart 2. Similar methodologies may be employed to incorporate other redox platforms, such as salens, ${ }^{41,42}$ into the Hangman architecture.

The unique structural motif of the Hangman architecture captures the essence of heme hydroperoxidase enzymes by precisely positioning an acid-base functional group over the face of heme. The heme hydroperoxides may be divided into subclasses of peroxidases, catalases and cytochrome P450 monooxygenases The hanging acid-base group mimics amino acid residues that orient water in the distal cavities of these enzymes to finely tune heme electronic structure and redox potential, as well as providing a proton relay during multielectron catalysis. For example, Figure 8 shows the distal side of cytochrome P450 (BM-3 structure), where a water channel is established by a threonine residue which holds the terminal water molecule in place above the heme. ${ }^{43}$ The same structure is captured by the Hangman porphyrin motif.
$\mathrm{X}$-ray crystallography reveals that the hanging group plays the role of threonine on the distal side of the Hangman porphyrin by preorganizing a water molecule above the Hangman cleft. ${ }^{44}$ Spectroscopic experiments show that the water binding is chemically reversible with an energy of $5.8 \mathrm{kcal} / \mathrm{mol}^{45}$ The Hangman construct is thus a faithful model of metalloenzymes with engineered distal sites but with greatly reduced complexity since secondary and tertiary protein structure are not required to impose the proton transfer network proximate to the heme redox center. ${ }^{46}$

The diversity of biological redox processes performed by the heme hydroperoxidase enzymes is achieved by $\mathrm{O}-\mathrm{O}$ bond activation via Compound I (Cpd I), ${ }^{47}$ which is two redox levels above $\mathrm{Fe}^{\mathrm{III}}$ with a ferryl $\mathrm{Fe}^{\mathrm{IV}}=\mathrm{O}$ and associated radical (e.g., a porphyrin $\pi$ radical cation, $\mathrm{P}^{\bullet+}$, in horseradish peroxidase and catalase, or an oxidized tryptophan in cytochrome $c$ peroxidase). It is generated by heterolysis of an $\mathrm{O}-\mathrm{O}$ bond in $\mathrm{H}_{2} \mathrm{O}_{2}$ or $\mathrm{O}_{2}$. Heterolytic cleavage to release $\mathrm{H}_{2} \mathrm{O}$ is accomplished by an internal redox disproportionation coupled to the delivery of a $\mathrm{H}^{+}$, from a precisely positioned acid-base residue in the active site cavity, to the distal oxygen atom in a Fe ${ }^{\mathrm{III}}-\mathrm{OOH}$ complex. ${ }^{48}$ We have confirmed a parallel oxygen activity for the Hangman porphyrins using cryogenic stopped-flow methods. ${ }^{49}$ No $\mathrm{O}-\mathrm{O}$ bond homolysis is observed, even under conditions that are known to favor the $\mathrm{Fe}^{\mathrm{IV}}=\mathrm{O}$ group of Compound II (Cpd II) formation in non-Hangman model heme cofactors such as tetramesitylporphyrin. ${ }^{50}$ Stoppedflow spectra show that the presence of the $\mathrm{H}^{+}$donor pendent group exerts kinetic control over O-O bond activation by exclusively favoring a proton-coupled $2 \mathrm{e}^{-}$ heterolysis, to produce Cpd I, over the competing $1 \mathrm{e}^{-}$ homolysis pathway attendant to Cpd II formation (Figure 9). Formation of Cpd I is thus accomplished by coupling proton transfer to a two-electron redox event of the heme cofactor, in much the same way the proton is used to drive the two-electron reactivity of the superoxide Pacman complex in Figure 7. A similar reactivity is observed for redox platforms other than porphyrins as well. $\mathrm{O}-\mathrm{O}$ bond heterolysis to produce $\mathrm{Mn}(\mathrm{V})=\mathrm{O}$ intermediates is preferred for salens adorned with hanging acid groups. ${ }^{51}$
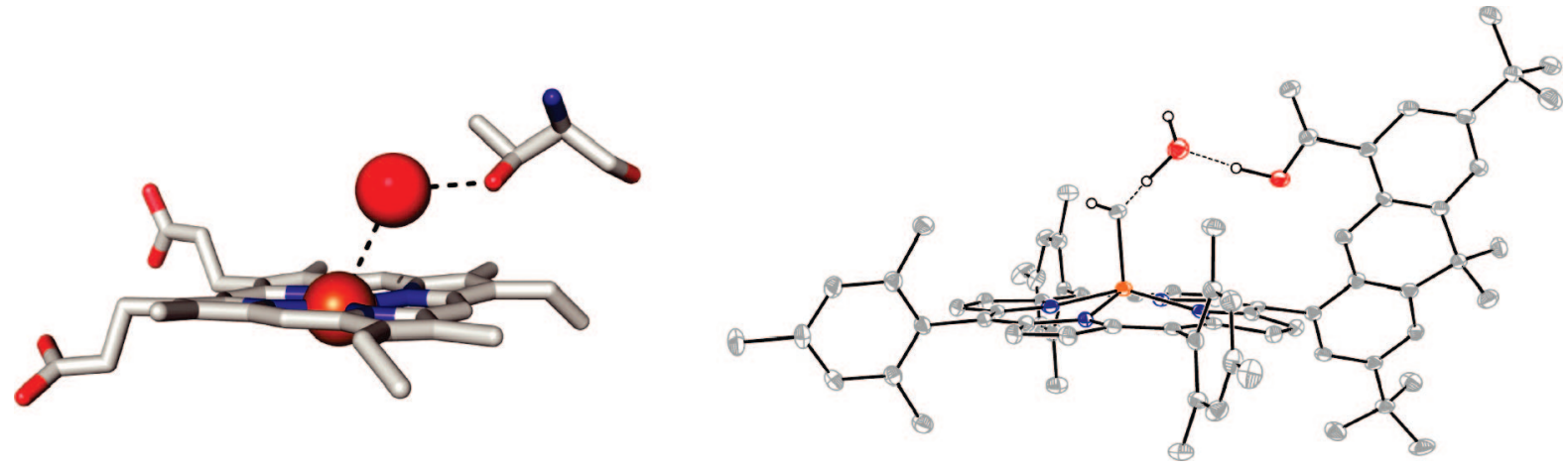

FIGURE 8. Graphical juxtaposition of the structurally characterized hydrogen-bonded water channel of P450 (left) and a monomeric iron(III) Hangman heme model system (right). The pendant carboxylic acid of the Hangman system plays a role analogous role of the distal threonine of the enzymatic system, which acts to preorganize the bound water molecule within the enzymatic heme cleft. 


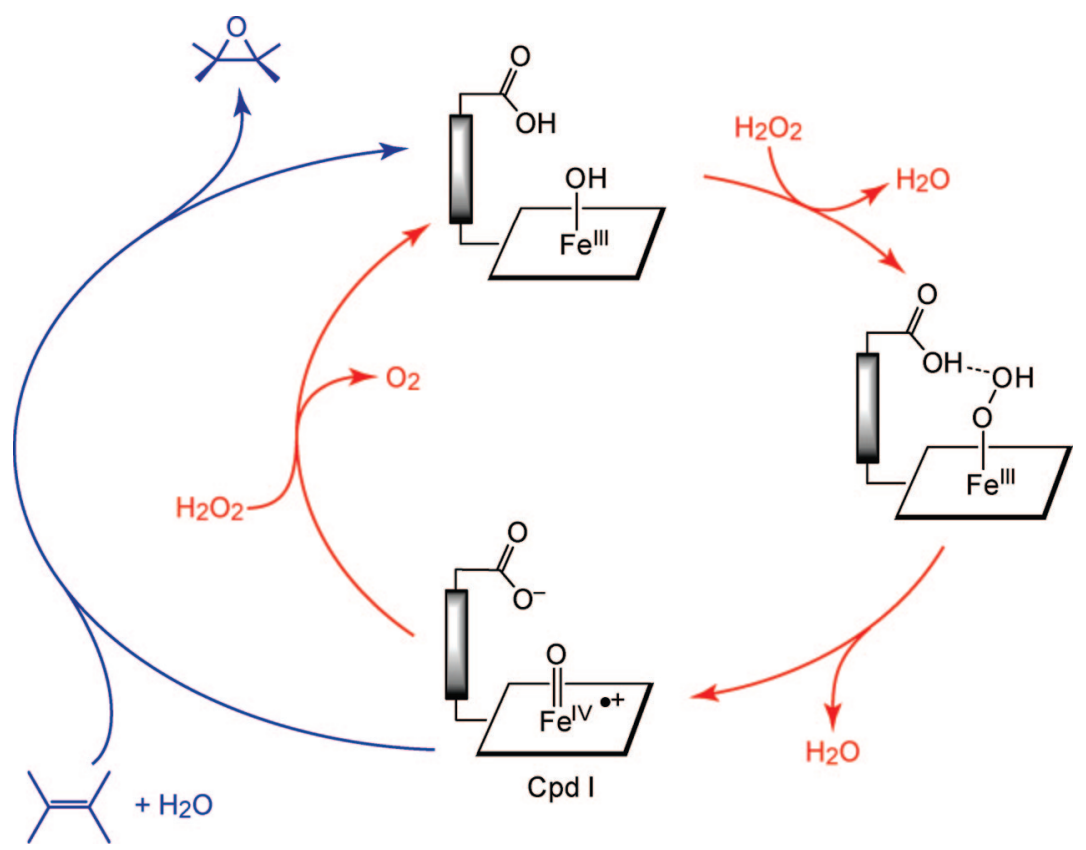

FIGURE 9. Cycle for both catalase and epoxidation reactivity from a single Fe(III) Hangman platform. The initial reaction steps are identical for both reaction pathways: $\mathrm{H}_{2} \mathrm{O}_{2}$ binding and heterolytic $\mathrm{O}-\mathrm{O}$ bond cleavage to generate a Cpd l-type intermediate. This ferryl intermediate can then oxidize either a second equivalent of $\mathrm{H}_{2} \mathrm{O}_{2}$ to generate $\mathrm{O}_{2}$ (catalase reactivity) or an organic substrate such as an olefin via an oxygen atom transfer reaction. The epoxidation chemistry is typically observed only when the iron Hangman center is replaced with the corresponding manganese derivative.

This proton-controlled, two-electron (heterolysis) versus one-electron (homolysis) redox specificity sheds light on the catalytic performance of Hangman cofactors. Figure 9 summarizes the PCET O-O bond chemistry at porphyrin and salen redox platforms. Facile P450 like epoxidation of olefins is observed at high rates of turnover $\left(>10^{3}\right)$ when manganese Hangman complexes are employed. In the absence of substrate, the Cpd I-type intermediate reacts with peroxide to generate oxygen and water in a catalase-like reactivity, also at an exceptionally high rate of turnover $\left(>10^{3}\right) .{ }^{45}$ The hanging group not only provides a site for proton transfer but also preorganizes substrate within the Hangman cleft. Oxidation and catalase activities are lost when the scaffold is extended and the proton must transfer over a long distance or when the $\mathrm{p} K_{\mathrm{a}}$ of the hanging acid-base group is increased. ${ }^{45,52}$ A similar reactivity is observed for Hangman salen complexes of manganese. ${ }^{41,42}$

The studies on these Hangman porphyrins and salen macrocycles clearly demonstrate that exceptional $\mathrm{O}-\mathrm{O}$ bond catalysis may be achieved when redox and proton transfer properties of a cofactor are controlled independently. A key requirement is that the proton transfer distance is kept short, which is accomplished by orthogonalizing redox and proton transfer coordinates ${ }^{53}$ in the Hangman construct. The benefit of this approach is that a multifunctional $\mathrm{O}-\mathrm{O}$ bond activity of a single redox scaffold is achieved by additionally controlling the proton equivalency at the redox platform. This observation is evocative of natural heme-dependent proteins that employ a conserved protoporphyrin IX cofactor to affect a myriad of chemical reactivities of the heme hydroperoxidases.

\section{Summary and Outlook}

The effective utilization of the dioxygen molecule in biological and chemical catalysis is predicated on the dual control of electron and proton inventories. With regard to $\mathrm{O}_{2}$ reduction, the coupled management of proton and electron equivalents is critical for selecting the $4 \mathrm{e}^{-} / 4 \mathrm{H}^{+}$ pathway to produce water over the $2 \mathrm{e}^{-} / 2 \mathrm{H}^{+}$pathway to produce peroxide. A substantial body of previous work on DPA and DPB Pacman porphyrins has clarified important structural attributes of an effective catalyst architecture, including the restriction of macrocyclic subunits to a faceto-face arrangement with minimal lateral displacements while allowing sufficient vertical flexibility for binding and activation of the $\mathrm{O}_{2}$ substrate. We have shown that this property of dimensional control may be augmented by using the scaffold to tailor the secondary coordination sphere of a redox-active center for PCET reactivity. The ability to bring these two features of oxidation-reduction and protonation states together by use of the xanthene and dibenzofuran scaffolds offers a powerful new tool for oxygen activation. As observed in biological energy transduction, the proper proton inventory can drive the reduction of oxygen by promoting the addition of three electrons to dioxygen, thereby driving $\mathrm{O}-\mathrm{O}$ bond cleavage. The $\mathrm{p} K_{\mathrm{a}}$ of the oxygen-bound species may be affected electronically by the presence of the second porphyrin of the Pacman motif such that protonation drives a $1 \mathrm{e}^{-} \rightarrow 1 \mathrm{H}^{+}$ $\rightarrow 2 \mathrm{e}^{-}$cascade to effect $\mathrm{O}-\mathrm{O}$ bond cleavage. These results are general and may be pertinent to other redox-active macrocycles. Kadish and co-workers have shown that the selective reduction of $\mathrm{O}_{2}$ to water ${ }^{54}$ can be accomplished using $\mathrm{Co}_{2}$ (III,III) biscorrole Pacman $^{55}$ and porphyrin-cor- 
role Pacman assemblies ${ }^{56}$ even when the porphyrin macrocycle is unmetallated. ${ }^{57}$ The role of the second macrocycle in tuning the $\mathrm{p} K_{\mathrm{a}}$ of the oxygen-bound species may be fulfilled by a noncoordinated Brönsted or Lewis acidbase site. On this latter count, the Hangman porphyrins come to the fore. The Hangman construct allows for precise control over the proton donating ability of an acid-base group poised over a redox-active metalloporphyrin redox site. Working in concert, the acid-base hanging group and redox macrocycle can catalytically promote $\mathrm{O}-\mathrm{O}$ bond cleavage at high efficiencies. By faithfully reproducing the presence of an acid-base group, the oxidation catalysis of heme hydroperoxidase cofactors is captured outside the protein milieu.

Finally, the $\mathrm{O}-\mathrm{O}$ bond activation process, especially that involving the conversion of oxygen to water, is of profound consequence to one of the greatest challenges facing our planet in the coming century, the development of a clean and renewable fuel source. ${ }^{58-61}$ Most directly, new catalysts are needed for $\mathrm{O}_{2}$ reduction at the cathode of fuel cells. The $\mathrm{O}_{2}$ reduction (and attendant proton transport) process is a singularly limiting factor governing power efficiencies in fuel cells, ${ }^{62}$ yet the $\mathrm{O}_{2}$ reduction problem steps beyond fuel consumption and points the way to the design of new sources of supply and storage. As first noted by Babcock, ${ }^{63}$ the $\mathrm{O}_{2}$ bond breaking chemistry of Nature's biofuel cell, $\mathrm{CcO}$, is the reverse of the $\mathrm{O}_{2}$ bond making chemistry of Nature's solar energy converter, Photosystem II (PS II). Oxygen binding in $\mathrm{CcO}$ binding is followed by the reaction with the side chain to produce a tyrosyl radical and the $\mathrm{Fe}^{4+}$-oxo ferryl and $\mathrm{Cu}^{2+}$-hydroxy species. In PS II, the reverse occurs; a tyrosyl radical produces an oxo, proximate to hydroxide to form a transient peroxy species, which then yields $\mathrm{O}_{2}$. The key intermediate in the critical bond-forming step of water oxidation or bondbreaking step of oxygen activation is a preorganized oxo/ hydroxyl intermediate. To this end, the $\mathrm{O}_{2} \rightarrow \mathrm{H}_{2} \mathrm{O}$ reduction process provides a guidepost for the design of catalysts that can promote the $\mathrm{H}_{2} \mathrm{O} \rightarrow \mathrm{O}_{2}$ oxidation process of solar-driven water splitting.

J.R. thanks the Fannie and John Hertz Foundation for a predoctoral fellowship. The work described in this Account has been supported by grants from the NIH (GM47274), DOE (DEFG02-05ER15745), NSF (CHE-0132680), and AFOSR (FA 9950-061-0011).

\section{References}

(1) Schultz, B. E.; Chan, S. I. Structures and proton-pumping strategies of mitochondrial respiratory enzymes. Annu. Rev. Biophys. Biomol. Struct. 2001, 30, 23-65.

(2) Kadenbach, B. Intrinsic and extrinsic uncoupling of oxidative phosphorylation. Biochim. Biophys. Acta 2003, 1604, 77-94.

(3) Bard, A. J.; Parsons, R.; Jordan, J. Standard Potentials in Aqueous Solution; Marcel Dekker: New York, 1985.

(4) Braenden, G.; Pawate, A. S.; Gennis, R. B.; Brzezinski, P. Controlled uncoupling and recoupling of proton pumping in cytochrome $\mathrm{C}$ oxidase. Proc. Natl. Acad. Sci. U.S.A. 2006, 103, 317-322.

(5) Hosler, J. P.; Ferguson-Miller, S.; Mills, D. A. Energy transduction: Proton transfer through the respiratory complexes. Annu. Rev. Biochem. 2006, 75, 165-187.

(6) Wikström, M. Cytochrome c oxidase: 25 years of the elusive proton pump. Biochim. Biophys. Acta 2004, 1655, 241-247.
(7) Winter, M.; Brodd, R. J. What are batteries, fuel cells, and supercapacitors? Chem. Rev. 2004, 104, 4245-4270.

(8) Collman, J. P.; Wagenknecht, P. S.; Hutchison, J. E. Cofacial bis(metallo)diporphyrins as potential molecular catalysts for multielectron reductions and oxidations of small molecules. Angew. Chem., Int. Ed. 1994, 33, 1537-1554 and references therein.

(9) Chang, C. K.; Liu, H. Y.; Abdalmuhdi, I. Electroreduction of oxygen by pillared cobalt(II) cofacial diporphyrin catalysts. J. Am. Chem. Soc. 1984, 106, 2725-2726.

(10) Le Mest, Y.; Inisan, C.; Laouenan, A.; L'Her, M.; Talarmain, J.; El Khalifa, M.; Saillard, J. Y. Reactivity toward dioxygen of dicobalt face-to-face diporphyrins in aprotic media. Experimental and theoretical Aspects. Possible mechanistic implication in the reduction of dioxygen. J. Am. Chem. Soc. 1997, 119, 6905-6106.

(11) Lui, H.-Y.; Abdalmuhdi, I.; Chang, C. K.; Anson, F. C. Catalysis of the electroreduction of dioxygen and hydrogen peroxide by an anthracene-linked dimeric cobalt porphyrin. J. Phys. Chem. 1985, 89, 665-670.

(12) Fillers, J. P.; Ravichandran, K. G.; Abdalmuhdi, I.; Tulinsky, A.; Chang, C. K. Crystal and molecular structure of anthracene and biphenylene pillared cofacial diporphyrins. J. Am. Chem. Soc. 1986, 108, 417-424.

(13) Nowick, J. S.; Ballester, P.; Ebmeyer, F.; Rebek, J., Jr. Convergent functional groups. 9. Complexation in new molecular clefts. J. Am. Chem. Soc. 1990, 112, 8902-8906.

(14) Schwartz, E. B.; Knobler, C. B.; Cram, D. J. Host-guest complexation. 65. Six new saddle shaped hosts based on fused dibenzofuran units. J. Am. Chem. Soc. 1992, 114, 10775-10784.

(15) Chang, C. J.; Deng, Y.; Heyduk, A. F.; Chang, C. K.; Nocera, D. G. Xanthene-bridged cofacial bisporphyrins. Inorg. Chem. 2000, 39, 959-966.

(16) Young, R.; Chang, C. K. Synthesis and characterization of blocked and ligand-appended hemes derived from atropisomeric mesodiphenylporphyrins. J. Am. Chem. Soc. 1985, 107, 898-909.

(17) Rosenthal, J.; Nocera, D. G. Oxygen activation chemistry of pacman and hangman porphyrin architectures based on xanthene and dibenzofuran spacers. Prog. Inorg. Chem. 2007, 54, in press.

(18) Chang, C. J.; Baker, E. A.; Pistorio, B. J.; Deng, Y.; Loh, Z.-H.; Miller, S. E.; Carpenter, S. D.; Nocera, D. G. Structural, spectroscopic, and reactivity comparison of xanthene- and dibenzofuran-bridged cofacial bisporphyrins. Inorg. Chem. 2002, 41, 3102-3109.

(19) Deng, Y.; Chang, C. J.; Nocera, D. G. Direct observation of the "pacman" effect from dibenzofuran-bridged cofacial bisporphyrins. J. Am. Chem. Soc. 2000, 122, 410-411.

(20) Pistorio, B. J.; Chang, C. J.; Nocera, D. G. phototriggered molecular spring for aerobic catalytic oxidation reactions. J. Am. Chem. Soc. 2002, 124, 7884-7885.

(21) Hodgkiss, J. M.; Chang, C. J.; Pistorio, B. J.; Nocera, D. G. Transient absorption studies of the pacman effect in spring-loaded diiron(III) m-oxo bisporphyrins. Inorg. Chem. 2003, 42, 8270-8277.

(22) Rosenthal, J.; Pistorio, B. J.; Chng, L. L.; Nocera, D. G. Aerobic catalytic photooxidation of olefins by an electron-deficient pacman bisiron(III) m-oxo porphyrin. J. Org. Chem. 2005, 70, 1885-1888.

(23) Rosenthal, J.; Luckett, T. D.; Hodgkiss, J. M.; Nocera, D. G. Photocatalytic oxidation of hydrocarbons by a bis-iron(III)-m-oxo pacman porphyrin using $\mathrm{O}_{2}$ and visible light. J. Am. Chem. Soc. 2006, 128, 6546-6547.

(24) Loh, Z.-H.; Miller, S. E.; Chang, C. J.; Carpenter, S. D.; Nocera, D. G. Excited-state dynamics of cofacial pacman porphyrins. J. Phys. Chem. A 2002, 106, 11700-11708.

(25) Chang, C. J.; Loh, Z.-H.; Deng, Y.; Nocera, D. G. The Pacman effect: A supramolecular strategy for controlling the excited-state dynamics of pillared cofacial bisporphyrins. Inorg. Chem. 2003, 42, 82628269.

(26) Chang, C. J.; Deng, Y.; Peng, S.-M.; Lee, G.-H.; Yeh, C.-Y.; Nocera, D. G. A convergent synthetic approach using sterically demanding aryldipyrrylmethanes for tuning the pocket sizes of cofacial bisporphyrins. Inorg. Chem. 2002, 41, 3008-3016.

(27) Chng, L. L.; Chang, C. J.; Nocera, D. G. meso-Tetraaryl cofacial bisporphyrins delivered by Suzuki cross-coupling. J. Org. Chem. 2003, 68, 4075-4078.

(28) Taube, H. Interaction of dioxygen species and metal ions: Equilibrium aspects. Prog. Inorg. Chem. 1986, 34, 607-625.

(29) Shi, C.; Anson, F. C. Multiple intramolecular electron transfer in the catalysis of the reduction of dioxygen by cobalt meso-tetrakis(4pyridyl)porphyrin to which four $\mathrm{Ru}\left(\mathrm{NH}_{3}\right)_{5}$ groups are coordinated. J. Am. Chem. Soc. 1991, 113, 9564-9570.

(30) Ricard, D.; Andrioletti, B.; L'Her, M.; Boitrel, B. Electrocatalytic reduction of dioxygen to water by tren-capped porphyrins, functional models of cytochrome c oxidase. Chem. Commun. 1999, 1523-1524. 
(31) Boulatov, R.; Collman, J. P.; Shiryaeva, I. M.; Sunderland, C. J. Functional analogues of the dioxygen reduction site in cytochrome oxidase: Mechanistic aspects and possible effects of CuB. J. Am. Chem. Soc. 2002, 124, 11923-11935.

(32) Collman, J. P.; Devaraj, N. K.; Decreau, R. A.; Yang, Y.; Yan, Y.; Ebina, W.; Eberspacher, T. A.; Chidsey, C. E. D. A cytochrome c oxidase model catalyzes oxygen to water reduction under ratelimiting electron flux. Science 2007, 315, 1565-1568.

(33) Chang, C. J.; Deng, Y.; Nocera, D. G.; Shi, C.; Anson, F. C.; Chang, C. K. Electrocatalytic four-electron reduction of oxygen to water by a highly flexible cofacial cobalt bisporphyrin. Chem. Commun. 2000, 1355-1356.

(34) Chang, C. J.; Loh, Z.-H.; Shi, C.; Anson, F. C.; Nocera, D. G. Targeted proton delivery in the catalyzed reduction of oxygen to water by bimetallic pacman porphyrins. J. Am. Chem. Soc. 2004, 126, 1001310020.

(35) Fukuzumi, S.; Okamoto, K.; Gros, C. P.; Guilard, R. Mechanism of four-electron reduction of dioxygen to water by ferrocene derivatives in the presence of perchloric acid in benzonitrile, catalyzed by cofacial dicobalt porphyrins. J. Am. Chem. Soc. 2004, 126, 10441-10449.

(36) Mair, R. D.; Graupner, A. J. Determination of organic peroxides by iodine liberation procedures. Anal. Chem. 1964, 36, 194-204.

(37) Morgan, J. E.; Verkhovsky, M. I.; Palmer, G.; Wikström, M. Role of the PR intermediate in the reaction of cytochrome $c$ oxidase with $\mathrm{O}_{2}$. Biochemistry 2001, 40,6882-6892.

(38) Blomberg, M. R. A.; Siegbahn, P. E. M.; Babcock, G. T.; Wikström, M. Modeling cytochrome oxidase: A quantum chemical study of the O-O bond cleavage mechanism. J. Am. Chem. Soc. 2000, 122, $12848-12858$

(39) Collman, J. P.; Boulatov, R.; Sunderland, C. J.; Fu, L. Functional analogues of cytochrome $\mathrm{c}$ oxidase, myoglobin, and hemoglobin Chem. Rev. 2004, 104, 561-588.

(40) Chang, C. J.; Yeh, C.-Y.; Nocera, D. G. Porphyrin architectures bearing functionalized xanthene spacers. J. Org. Chem. 2002, 67, 1403-1406.

(41) Liu, S.-Y.; Nocera, D. G. Hangman salophens. J. Am. Chem. Soc. 2005, 127, 5278-5279.

(42) Yang, J. Y.; Bachmann, J.; Nocera, D. G. Hangman salen platforms containing two xanthene scaffolds. J. Org. Chem. 2006, 71, 87068714.

(43) Haines, D. C.; Tomchick, D. R.; Machius, M.; Peterson, J. A. Pivotal role of water in the mechanism of P450BM-3. Biochemistry 2001 40, 13456-13465.

(44) Yeh, C.-Y.; Chang, C. J.; Nocera, D. G. “Hangman” porphyrins for the assembly of a model heme water channel. J. Am. Chem. Soc. 2001, 123, 1513-1514.

(45) Chang, C. J.; Chng, L. L.; Nocera, D. G. Proton-coupled O-O activation on a redox platform bearing a hydrogen-bonding scaffold. J. Am. Chem. Soc. 2003, 125, 1866-1876.

(46) Ozaki, S. I.; Roach, M. P.; Matsui, T.; Watanabe, Y. Investigations of the roles of the distal heme environment and the proximal heme iron ligand in peroxide activation by heme enzymes via molecular engineering of myoglobin. Acc. Chem. Res. 2001, 34, 818-825.

(47) Watanabe, Y. In The Porphyrin Handbook; Kadish, K. M., Smith, K. M., Guilard, R., Eds.; Academic Press: San Diego, 2000; Vol. 4, pp 97-117.
(48) Veitch, N. C., Smith, A. T. In Advances in Inorganic Chemistry; Academic Press: New York, 2001; Vol. 51, pp 107-162.

(49) Soper, J. D.; Kryatov, S. V.; Rybak-Akimova, E. V.; Nocera, D. G. Proton-directed redox control of $\mathrm{O}-\mathrm{O}$ bond activation by heme hydroperoxidase models. J. Am. Chem. Soc. 2007, 129, 5069-5075.

(50) Groves, J. T.; Haushalter, R. C.; Nakamura, M.; Nemo, T. E.; Evans, B. J. High-valent iron-porphyrin complexes related to peroxidase and cytochrome P-450. J. Am. Chem. Soc. 1981, 103, 2884-2886.

(51) Liu, S.-Y.; Soper, J. D.; Yang, J. Y.; Rybak-Akimova, E. V.; Nocera, D. G. Mechanistic studies of hangman salophen-mediated activation of O-O bonds. Inorg. Chem. 2006, 45, 7572-7574.

(52) Chng, L. L.; Chang, C. J.; Nocera, D. G. Catalytic O-O activation chemistry mediated by iron hangman porphyrins with a wide range of proton-donating abilities. Org. Lett. 2003, 5, 2421-2424.

(53) Reece, S. Y.; Hodgkiss, J. M.; Stubbe, J.; Nocera, D. G. Protoncoupled electron transfer: The mechanistic underpinning for radical transport and catalysis in biology. Philos. Trans. R. Soc. London, Ser. B 2006, 361, 1351-1364.

(54) Kadish, K. M.; Fremond, L.; Ou, Z.; Shao, J.; Shi, C.; Anson, F. C.; Burdet, F.; Gros, C. P.; Barbe, J. M.; Guilard, R. Cobalt(III) corroles as electrocatalysts for the reduction of dioxygen: Reactivity of a monocorrole, biscorroles, and porphyrin-corrole dyads. J. Am. Chem. Soc. 2005, 127, 5625-5631.

(55) Guilard, R.; Burdet, F.; Barbe, J. M.; Gros, C. P.; Espinosa, E.; Shao, J.; Ou, Z.; Zhan, R.; Kadish, K. M. Heterobimetallic complexes of cobalt(IV) porphyrin-corrole dyads. Synthesis, physicochemical properties, and X-ray structural characterization. Inorg. Chem. 2005, 44, 3972-3983.

(56) Kadish, K. M.; Ou, Z.; Shao, J.; Gros, C. P.; Barbe, J. M.; Jerome, F.; Bolze, F.; Burdet, F.; Guilard, R. Alkyl and aryl substituted corroles. 3. Reactions of cofacial cobalt biscorroles and porphyrincorroles with pyridine and carbon monoxide. Inorg. Chem. 2002, $41,3990-4005$

(57) Kadish, K. M.; Shao, J.; Ou, Z.; Fremond, L.; Zhan, R.; Burdet, R.; Barbe, J. M.; Gros, C. P.; Guilard, R. Electrochemistry, spectroelectrochemistry, chloride binding, and $\mathrm{O}_{2}$ catalytic reactions of free-base porphyrin-cobalt corrole dyads. Inorg. Chem. 2005, 44, 6744-6754

(58) Nocera, D. G. On the future of global energy. Dædulus 2006, 135, $112-115$

(59) Lewis, N. S.; Nocera, D. G. Powering the planet: Chemical challenges in solar energy utilization. Proc. Natl. Acad. Sci. U.S.A. 2006, 103, 15729-15735.

(60) Dempsey, J. L.; Esswein, A. J.; Manke, D. R.; Rosenthal, J.; Soper, J. D.; Nocera, D. G. Molecular chemistry of consequence to renewable energy. Inorg. Chem. 2005, 44, 6879-6892.

(61) Nocera, D. G. Vision of the future from the past. Chem. Eng. News 2001, 79, 250.

(62) Adler, S. B. Factors governing oxygen reduction in solid oxide fuel cell cathodes. Chem. Rev. 2004, 104, 4791-4843.

(63) Hoganson, C. W.; Pressler, M. A.; Proshlyakov, D. A.; Babcock, G. T. From water to oxygen and back again: Mechanistic similarities in the enzymatic redox conversions between water and dioxygen. Biochim. Biophys. Acta 1998, 1365, 170-174.

\section{AR7000638}

